\title{
Fysisk aktivitet och hälsa: epidemiologi och mekanismer
}

\author{
Bengt Saltin och Bente K. Pedersen
}

Copenhagen Muscle Research Centre, Rigshospitalet och Köpenhamns Universitet, Köpenhamn, Denmark

\section{A bstract}

Physical inactivity is strongly associated with an enhanced risk for premature disease and death. With more people becoming physically inactive, this risk factor is today as important as smoking in many countries and more important than obesity.

At the mechanistic level the focus is on the muscle metabolic capacity/fitness, because it is critical for the development of metabolic-related diseases. Skeletal muscle is an extraordinary plastic tissue and to maintain a good metabolic capacity regular physical activity is needed. High metabolic fitness is a prerequisite for an optimal oxidation of fat at rest and during exercise, and good glucose handling by the muscle. The exercise-induced gene expression is of short duration ( $\sim 24-28$ hours), which implies that a certain regularity of physical activity is required to maintain a high metabolic fitness, which is a function of how much the muscles are used. Even low levels of physical activity have a beneficial effect when perfomed regularly on metabolic fitness and thus, for the overall health of the individual.

Keywords: Physical activity; health; muscle enzymes; metabolic syndrome; metabolic fitness.

\section{Introduktion}

Den grekiska läkaren Herodices skrev 480 BC: "Att äta förnuftigt är inte tillräckligt för att hâlla sig frisk; man måste också vara fysiskt aktiv". En riktig konklusion som dock ej blivit vetenskapligt belagd förrän under senare år. I gengäld är bevisen i dag övertygande. Det gäller epidemiologiska data såväl som förståelsen för vilka de mekanismer är som gör att en fysiskt aktiv livstil positivt påverkar en individs hälsa. De första epidemiologiska studier som visade en ökad risk för prematur sjukdom och död vid att vara fysiskt inaktiv fokuserade på hjärt-kärlsjukdomar och kardiovaskulär kapacitet (1). Senare studier har också bekräftat att när denna, mätt som maximal syreupptagning (konditionstal) är låg, så är risken ökad (2). Ju mera syre som kan transporteras till kroppens vävnad, desto högre är den maximala syreupptagningen. Parallellt med denna centrala adaptation till ökad fysisk aktivitet påverkas den i träningen engagerade skelettmuskulaturen (3). Den metabola kapaciteten förbättras genom att involverade enzymer och transportproteiner i ämnesomsättningen ökar. En kritisk problematik är den roll som den aeroba jmf. med den metabola kapaciteten/ fitness spelar för att förklara relationen mellan en fysiskt aktiv livstil och hälsa. Träning, som förbättrar skelettmuskulaturens metabola ämnesomsättning och därmed muskulaturens metabola fitness är kanske den primära förklaringen.

\section{Epidemiologiska studier}

Morris et al.s studie från 1953 visade att konduktörer på dubbeldäckbussar i London hade en lägre insjukningsfrekvens och dödlighet $\mathrm{i}$ ischemisk hjärtsjukdom än de stillasittande busschaufförerna (1). Sedan dess har stringensen i undersökningarna alltmer ökat och resultaten blivit än klarare. Samhällsutvecklingen under den sista halvan av 1900-talet har bidragit till detta. Vad som skett är att fysiska belastningen på arbetsplatsen ej diskriminerar längre. Det är istället individens fysiska aktivitet på fritiden som är avgörande. Denna har också avtagit bland allt fler personer i många länder, vilket gör att fysisk inaktivitet i dag framträder som en allt starkare riskfaktor. Ett exempel som illustrerar utvecklingen är studien av 1913 års män i Göteborg. När de undersöktes som 54 åringer på 1960-talet hade de en kondition snivå som var över den som ger en markant ökad risk för tidig sjukdom och död (4). Något säkert samband mellan deras fysiska aktivitet och sjukdom och död kunde därmed ej heller dokumenteras (5). Tre decennier senare är fysisk inaktivitet pa fritiden en stark riskfaktor i Sverige liksom i många andra länder där bl.a. motorisering ersätter gång och cykel för daglig transport (6). 
Table I. Sammanställning av resultat fran epidemiologiska studier över riskfaktorer för kardiovaskulär sjukdom: Relativ risk (RR) för prematur död, och "population attributable risk" (PAR; populationens risk $=$ relativ risk $\times$ frekvens i befolkningen)

\begin{tabular}{lll}
\hline Risk factor & RR (range) & PAR (range) \\
\hline Inactive lifestyle & $1.4-1.9$ & $22.1-39.0$ \\
Smoking & $1.3-2.4$ & $9.5-32.9$ \\
Cholesterol level & $1.4-2.0$ & $9.4-20.6$ \\
Hypertension & $1.4-2.2$ & $5.7-15.3$ \\
Overweight & $1.2-1.4$ & $2.9-5.7$ \\
\hline
\end{tabular}

Sammanställning fran Haapanen-Niemi et al. (6).

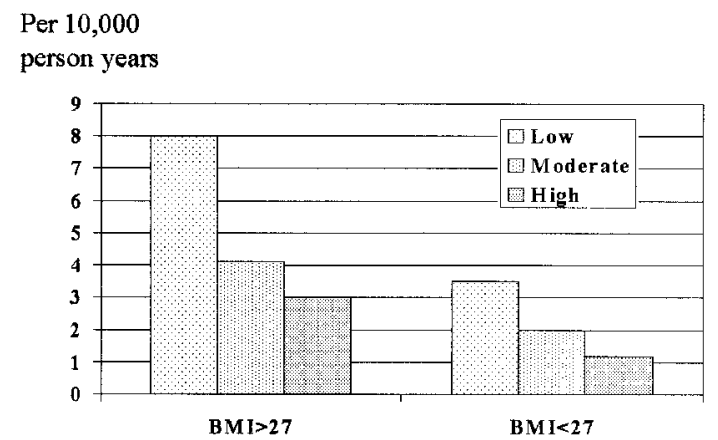

Fig. 1. Relativ risk för uppkomst av typ II diabetes för personer med en "body mass index" (BMI) över och under 27 i relation till fitness (9).

Haapanen-Niemi och kollegor (6) har sammanfattat litteraturen vad gäller olika riskfaktorers relativa roll i relation till prematur död (Table 1). Bilden är klar. Att vara fysiskt inaktiv innebär en risk som är lika stor som för rökning och helt på nivå med höga blodfettvärden och hypertension. Värt att notera är att vara överviktig medför en väsentligt lägre risk. I ett samhällsperspektiv är "population attributable risk" (PAR, relativ risk gånger frekven s i befolkningen) den intressanta variabeln. I och med att förekomsten av fysisk inaktivitet stiger i många länder, så stiger PAR för fysisk aktivitet också och blir den viktigaste riskfaktorn (Tabell 1). En förändring av den fysiska aktivitetsnivån - upp eller ner - får inom två år en direkt effekt på en minskad respektive ökad risk (7).

Av speciellt intresse är de epidemiologisk a undersökningar där betydelsen av fysisk aktivitet värderats i relation till "body mass index" (BMI). Dessa studier visar ett likartat mönster oavsett om "endpoint" är sjukdom eller död som följd av hjärt-kärl sjukdom och typ II diabetes $(8,9)$. Även vid markant övervikt (BMI > 27) kan fysisk aktivitet kompensera för utveckling av typ II diabetes (Fig. 1).

\section{Aerob vs metabolisk fitness}

Efter några veckor med ökad aktivitetsgrad observeras några viktiga olikheter mellan utveckling av kondition å ena sidan och den mitokondriella kapaciteten a den andra. Inom de första veckorna ökar båda variablerna likartat. Därefter fortsätter mitokondriernas enzymaktivitet att stiga medan stigningen i kondition är avtagande (Fig. 2) (10). Efter 4-6 veckor är konditionen ökad med 15-20\% medan den mitokondriella enzymaktiviten är ökad

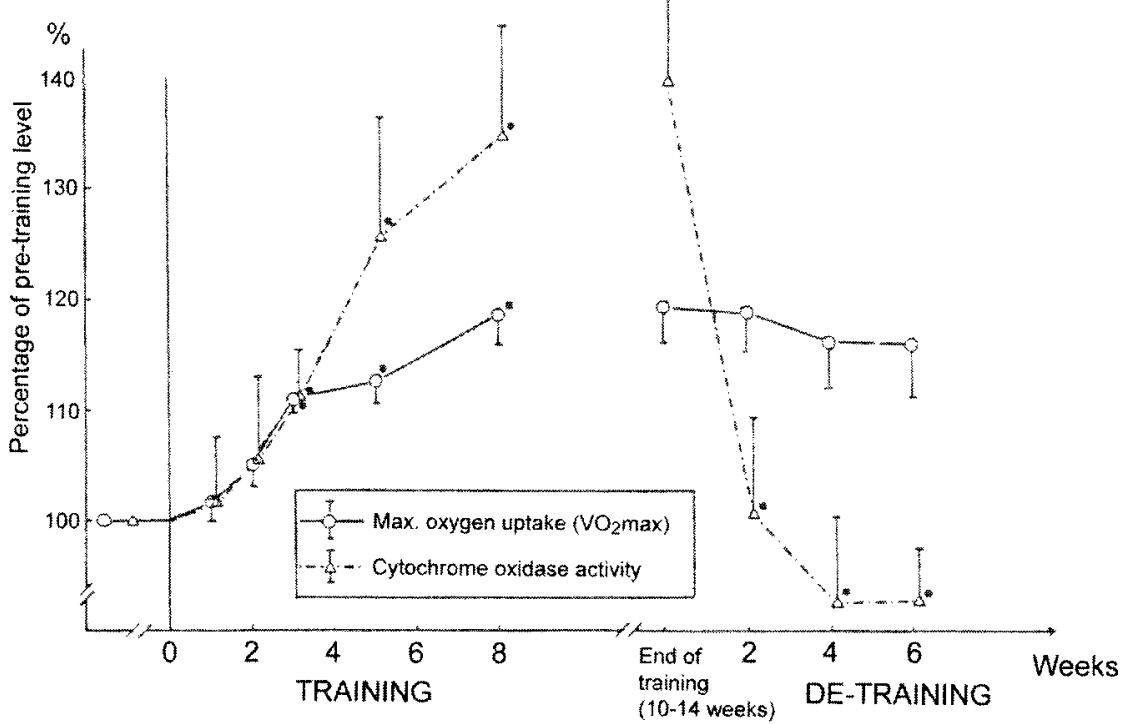

Fig. 2. Förändring i maximal syreupptagning och ett mitokondriellt enzym före, under och efter uthallighetsträning 3 gånger i veckan med moderat intensitet ( hjärtfrekvens ca. 160 slag $\left.\min ^{-1}\right)(10)$. 


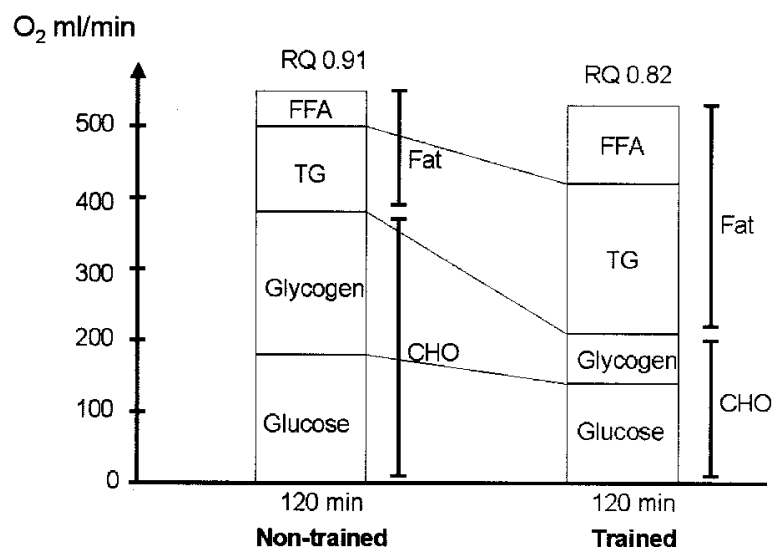

Fig. 3. Substratförbrukning i tränat och otränat ben när samma arbetsbelastning utförs (2). RQ: respiratory quotient; FFA: free fatty acids; TG: triglyceride; $\mathrm{CHO}$ : carbohydrate.

med det dubbla eller mera. Potentialen för aerob metabolism i muskelfibrerna ökar således markant och mer än "nödvändigt" för den maximala syreupptagningen. Detta ses ännu tyd ligare när otränade jämförs med vältränade personer. Differensen i kondition kan vara 50-60\% medan mitokondrie-täthet och enzymaktivitet är 4 gånger högre $(3,11)$. Det betyder att skelettmuskulaturen har en metabol överkapacitet vars storlek påverkas av träning. Skall benämningen "metabolic fitness" definieras, så kunde det vara kvoten mellan den mitokondriella kapaciteten till substratomsättning och muskelns maximala syreupptag.

En metabol överkapacitet bidrar till ett större fettutnyttjande i den tränade skelettmuskulaturen i vila och under muskelarbete (12). Det faktum att det är den lokala muskelanpassningen som primärt avgör muskelns substratval är ett viktigt fynd. Detta är visat bl.a. genom att låta försökspersoner träna ena benet och när detta är väl anpassat så utförs tvåbensarbete, d.v.s. "halva" arbetet görs med otränad muskulatur samtidigt som den andra "halvan" av arbetet utförs med tränade muskler. Den stora fettförbrukningen ses i det tränade benet och både fettsyror frân blodbanan och triglycerider (i blod och lagrade i muskeln) kan utnyttjas mer (Fig. 3) (12, 13). Det är inte bara den mitokondriella kapaciteten som förbättras med träning, utan också kapaciteten av transport av proteiner för glukos eller fettsyror in i muskelfibern (Fig. 4) (14, 15). Dessutom ökar lipoproteinlipasen (LPL) vilket bidrar till den ökade förbrukningen av triglycerider (S-TG) från blodet, när det passerar genom musklernas kapillärnät (13). Genom hydrolysen av S-TG ges möjlighet för en större HDL-kolesterol produktion. Det har visats att ju fler kapillärer och därmed LPL som finns i en muskel desto lägre är LDL-K/HDL-K hos i övrigt friska yngre män (16). Tränar dessa med moderat

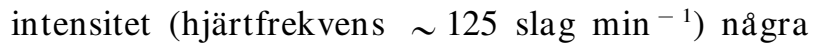
gånger i veckan under 6 veckor förbättras LDL-K/ HDL-K kvoten i relation till ökningen i muskelkapillarisering. Förbättringen i maximal syreupptagning var liten $\left(1.5 \mathrm{ml} \mathrm{kg}{ }^{-1}\right.$ per minut) men LDL-K/ HDL-K kvoten sjönk frân 2.4 till 1.9 vid en samtidig mindre reduktion i total kolesterol (Fig. 5) (17).

Med en större fettoxidation blir kolhydratförbränningen reducerad, vilket ses mest tydligt under arbete (12). Omedelbart skulle man därför förmoda att det sker en nedreglering av det i muskeln vikti-

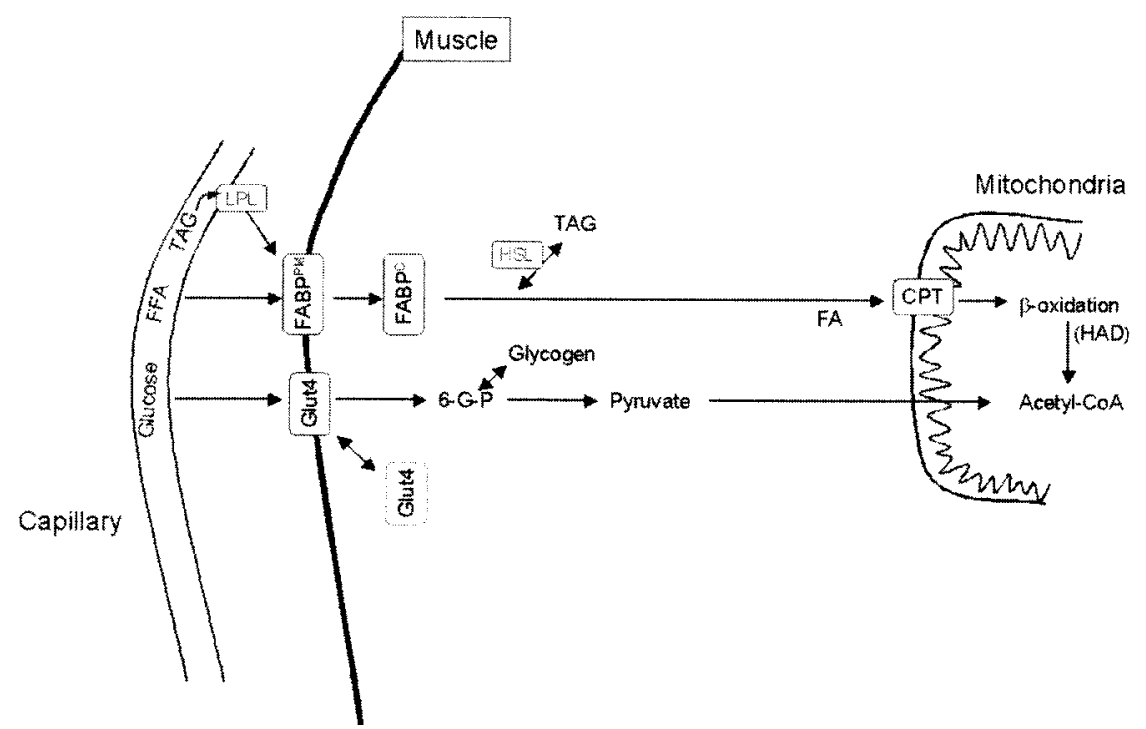

Fig. 4. Schematisk illustration av olika kritiska steg i muskelns ämnesomsättning. FFA: free fatty acid; FA: fatty acid; TAG: triacylglycerol; LPL: lipoproteinlipase; GLUT4: glucose transport protein $4 ; \mathrm{FABP}_{\mathrm{PM}}, \mathrm{FABP}_{\mathrm{C}}$ : fatty acid binding protein; HSL: hormone sensitive lipase; CPT: carnitine palmityl transferase; HAD: 3-hydroxy-CoA-dehydrogenase. 


\section{LDL-C/HDL-C}

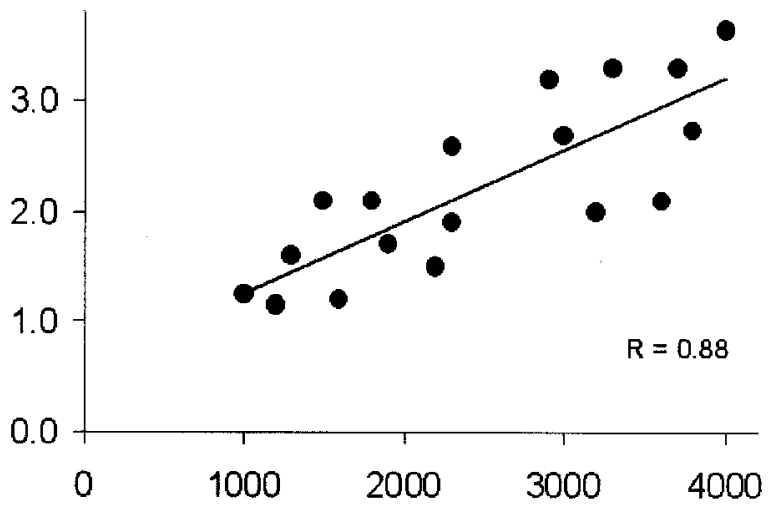

Fibre area per capillary $\left(\mu \mathrm{m}^{2}\right)$

Fig. 5. Low-density/high-density lipoprotein-kolesterol (LDL-K/ HDL-K) kvoten i relation till kapillarisering i skelettmuskulatur. $\mathrm{Ju}$ större fiberareal per kapillär desto färre kapillärer. Vid träning får de med hög kvot en reduktion av denna i relation till ökningen i muskelkapillarisering $(16,17)$.

gaste transportproteinet för glukos (GLUT4) och andra i omsättningen av socker involverade enzymer. Det är emellertid inte fallet. GLUT4 ökar med fysisk aktivitet både hos friska människor och hos typ II diabetiker, liksom det är fallet för hexokinas (HK), som fosforylerar glukos efter transport in i muskelcellen, och för glykogensyntas (GS), vilken är kritisk för glykogen inlagringen i muskeln (18-20). Trots detta är både glukosupptaget från blodbanan och glykogenatgången lägre under moderat arbete $i$ en tränad jämfört med en otränad muskel (13). Det talar för att den muskelkontraktionsstimulerade signaleringen som reglerar GLUT4 translokationen till plasmamembranet, också ändras med träning. Hur det sker är ej klarlagt. Det man vet är att denna signalering åtskiljer sig från den insulinmedierade translokationen av GLUT4 (21).

Det är väl klarlagt hur regleringen av muskelns glykogennedbrytning sker. Den är mindre i den tränade muskeln på grund av liten ackumulering av oorganiskt fosfat i den tränade muskeln (22). Det skall noteras att en större kapacitet för glukosmetabolism har en funktionell betydelse, vilket ses under intensivt muskelarbete, där muskelns glukosförbrukning är störst i den tränade muskeln (23). Dessutom medför den med träning förbättrade metabola kapaciteten en bättre muskulär insulinkänslighet hos både friska personer och typ II diabetiker över hela spektrat av insulinstimulering frân fysiologisk till farmakologisk nivå (19).

I en nyligen publicerad artikel samt en editorial berörs den ofta diskuterade frågan om motionens roll för att bibehålla sin kroppsvikt $(24,25)$. De kvinnor som varit mâttligt fysiskt aktiva på sin fritid $\left(\sim 3000 \mathrm{~kJ} \mathrm{day}^{-1}\right)$ under ett år bibehöll sin kroppsvikt. De som omsatte $\sim 30 \%$ lägre med energi på sin fritid ökade sin vikt med så mycket som $9.5 \mathrm{~kg}$ under året. Ett tal som dock bra passar med differensen i energiomsättning under âret förutsatt att energiintaget ej ändrats markant. Motionen påverkar således både fettmassa och skelettmuskulatur positivt.

\section{Dynamiken i metabol fitness och molekylär reglering}

Resultaten i Fig. 2 visar att inom 1 till 2 veckor efter att en person ökar eller minskar sin fysiska aktivitet ses en förändring i mitokondriernas enzymaktivitet med en uttalad tendens till att när fysiska aktiviteten upphör, så reduceras den i muskeln erhålna metabola förbättringen snabbare än det tog att bygga upp den $(3,10)$. Konditionen försämras också, men denna reduktion sker långsammare. Tidsrelationen mellan fysisk aktivitet och metabol fitness är således tätare och mera uttalad än mellan fysisk aktivitet och aerob fitness. Genexpression som följd av fysisk aktivitet är ovan beskriven på proteinivå. Dessa förändringar är icke alltid stora och det kan dröja upp till flera veckor innan en signifikant effekt kan påvisas. Mot denna bakgrund öppnas nya möjligheter med de molekylärbiologiska metoder som finns i dag till att studera genexpression pa transskriptionsnivå i human skelettmuskulatur (18).
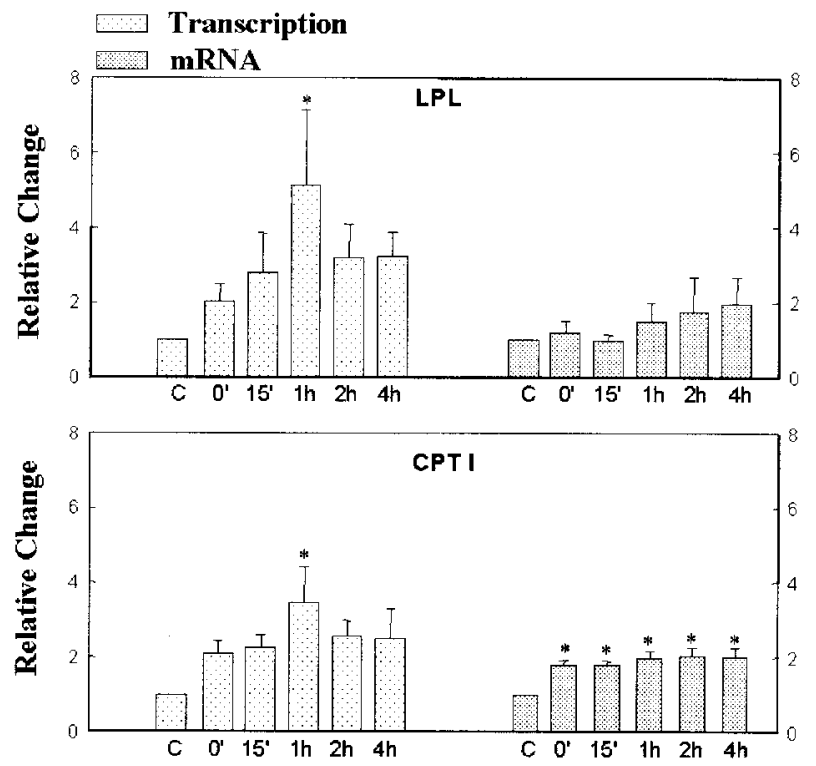

Fig. 6. Exempel pa transskriptionshastigheten och ackumulering av mRNA [lipoproteinlipase (LPL), carnitine palmityl transferase (CPT)] för två gener (LPL, CPT) som kodar för proteiner involverade i muskelns ämnesomsättning (18). 
Fysisk aktivitet några gånger eller ev. blott vid ett enstaka tillfälle har en effekt på vissa geners aktivitet. Det är muskelkontraktionen och den därmed ökade ämnesomsättningen i muskeln, som inducerar aktiveringen av de aktuella generna. Här ges några exempel.

När transskriptionshastigheten och ackumuleringen av mRNA bestäms för LPL genen under och efter cykling så stiger transskriptionshastigheten (18) och, med en viss fördröjning, också mR NA för LPL (Fig. 6) (18, 26). I återhämtningsfasen efter arbetet är genen fortsatt aktiverad några timmar, varefter transskriptionshastigheten ater minskar mot vilo nivå. Den ökade expressionen på mRNA nivå bibehålles ännu några timmar, om än oftast ej till nästa dag. Att proteinet transporteras till sin lokalisering inne i kapillären har tidigare påvisats och berörts ovan (13). Ett annat kritiskt enzym är 3-hydroxyacyl-CoA-dehydrogenase (HAD) som ingår i $\beta$-oxidationen av fettsyror i mitokondrierna. HAD och LPL har ett likartat mönster för förändringar på transskriptionsnivâ, med den mindre skillnaden att genen som kodar för HAD kommer igång långsammare. I gengäld varar mRNA ackumuleringen längre tid. Transportproteiner påverkas också av ett aktivitetstillfälle. Det gäller till exempel för karnitin palmityl transferase (CPT; transport av fettsyror över mitokondriemembranen) (Fig. 6) (18) och GLUT4 (20). Ändringen kommer dock snabbare för CPT än för GLUT4. Även expression av gener som kodar för enzymer som HK och GS påverkas akut $(18,27)$.

I dag kan man inte specifikt angiva vilka faktorer som inducerar aktiveringen av de metabola generna, dvs. "signaleringen" i muskelcellen är ej klarlagd. En roll för ämnesomsättningen kan dock påvisas för flera av de gener som har studerats $(28,29)$. När glykogenniva $n$ är låg vid arbetets start, sker en snabb ökning av transskriptionshastigheten och ackumuleringen av mRNA och den blir också mera markant. Det diskuteras om detta förklaras av en direkt effekt av den låga glykogennivån eller om det är relaterat till en större förbrukning av fettsyror.

Under arbete frigörs fettsyror i första hand från fettväven $(30,31)$ och en större fraktion av primärt fleromättade fettsyror inkorporeras i plasmamembranens fosfolipid-fraktioner vid en ökad fysisk aktivitet medan mättade fettsyror förbrukas företrädesvis i muskelcellens ämnesomsättning $(32,33)$. Som en följd av dessa fynd har det föreslagits att det är omsättningen av fettsyror i muskelcellen, som inducerar en aktivering av gener, som kodar för proteiner av betydelse för fettransport och oxidation
(34). Denna hypotes bygger på att fleromättade fettsyror, via en interaktion med "heat shock protein" (HSP)72, fungerar som ligand för PPAR receptorerna, vilka tillsammans med retenoid X-receptorn (RXR) aktiverar de gener, som kodar för bl.a. LPL, FABP och enzymer i $\beta$-oxidationen (29). När arbetet utförs av muskler med lagt glykogeninnehåll ökar HSP72 markant i muskeln. Proteinet har troligen sin primära funktion inne i muskelcellen, då det ej frisätts till blodbanan. Någon uppreglering av PPAR är ej påvisad med akut arbete eller träning, men behövs ev. ej då den kritiska faktorn kan vara uppregleringen av HSP72. Intag av kolhydrater och fett under eller efter pågående aktivitet kan ocksa ha en effekt på aktivering av flera av de metabola generna. Sa t.ex. avtar aktiveringen av LPL och HAD vid ett intag av kolhydrater timmarna efter ett träningstillfälle (35). Fynd som antyder en spännande interaktion mellan fysisk aktivitet och kost på ena sidan och muskeladaptation på den andra.

När en större mängd mättade fettsyror är tillgänglig än den som förbrukas i muskelns mitokondrier finns risk för att inlagringen av dessa fettsyror ökar i plasmamembranen, vilket medför att membranets fluiditet minskar (36). Dessutom inlagras TG inne i muskelcellen utan att det blir en samtidig ökning av "maskineriet" för fettomsättning. Följden av för lite motion blir därmed försämrad plasmamembranfluiditet, ökad muskel TG inlagring och liten PPAR-receptor-aktivering i skelettmuskulaturen. Detta kan vara förklaringen till att det föreligger en koppling mellan fettmetabolism och muskelns insulinkänslighet (36).

För omsättningen av glukos i organismen är skelettmuskulaturen den viktigaste vävnaden. Vid en oral glukostoleranstest liksom vid en euglukemisk clamp upptas cirka $80 \%$ av glukosen i skelettmuskulaturen. Muskelns insulinkänslighet avspeglas

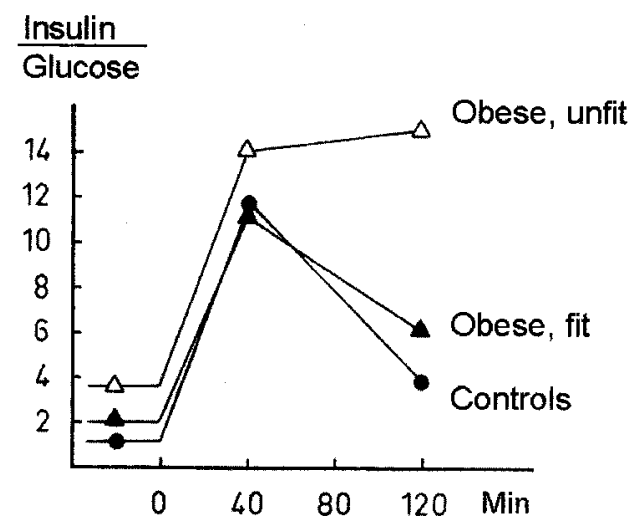

Fig. 7. Insulin/glukos kvoten under en oral glukostolerans test för kontroller, överviktiga tränade och otränade 48-åriga män (37). 
således i dessa mätningar (19). I linje med detta har det påvisats att glukosintoleranta personer som är feta, men vältränade har en normal insulin/glukos kvot i motsats till otränade, överviktiga personer (Fig. 7) (37). Detta fynd överensstämmer med de resultat som angavs ovan vilka visade att fysiskt aktiva överviktiga personer har en halverad risk för typ II diabetes (Fig. 1) (9). Viktigt är också att för glukosintoleranta personer är fysisk aktivitet en effektiv terapi för att normalisera insulinkänsligheten. Detta sker primärt genom att den tränade muskeln får ett större glukosupptag för en given insulinnivå i blodet. En effekt som är väl visad också hos typ II diabetiker bl.a. genom träning med ett ben (19). Den förbättrade insulinkänsligheten noterades enbart i det tränade benet. I det otränade benet är insulinkänsligheten oförändrad.

Det går ej i dag att exakt ange vilken eller vilka av alla de metabola anpassningar som sker vid bruk av muskulaturen som mest väsentligt bidrar till att muskulaturen blir mer känslig för insulin. Det viktiga är dock att den fysiska aktiviteten så markant förbättrar insulinets effekt på skelettmuskulaturen. Detta kan verka något förvånande när "signaleringen" vid translokationen av GLUT4 till plasmamembranen är olika för insulin och muskelkontraktion (21).

Innan diskussionen om effekten av muskelarbete och träning på typ II diabetes eller förstadier till denna sjukdom avslutas, skall några helt nya fynd presenteras (38). Muskelarbete medför en produktion speciellt av cytokinet interleukin-6 (IL-6). IL-6 specifikt mRNA är svårt att påvisa i en vilande muskel eftersom mängden är låg. Genen för IL-6 aktiveras dock fort under en arbetsperiod och transskriptionen är stor. Proteinet produceras kort efter att mRNA mängden i muskeln ökat och IL-6 frisätts till blodbanan. Hastigheten varmed transskriptionen sker och mängden protein som bildas är en funktion av arbetets duration men också av tillgången på glykogen i muskeln. Ju längre arbetstid och ju mindre glykogen desto mer IL-6 produceras och frisätts till blodbanan. Mot den bakgrunden är det ej förvånande att IL-6 har en hormonliknande verkan och bidrar till en ökad lipolys i fettväven. IL-6 har troligen också en annan effekt (38). Tumour necrosis factor- $\alpha$ (TNF- $\alpha$ ) produceras bl.a. i fettväven. Förutom att det är ett proinflammatoriskt cytokin och stimulerar arterogenes-progression bidrar TNF- $\alpha$ ocksa till minskad insulinkänslighet och typ II diabetes. Hypotesen är nu att IL-6 producerad i muskulaturen när den är aktiverad motverkar TNF- $\alpha$ :s negativa verkan (38).
Ett ytterligare stöd för denna roll för IL-6 kommer från genmanipulerade möss, som ej producerar IL-6 (39). De utvecklar insulinresistens och blir feta. När IL-6 ges till dessa möss normaliseras insulinresisten sen och vikten minskar.

\section{Sammanfattning}

De epidemiologiska resultaten som vuxit fram under de senaste 50 åren påvisar en alltmer dominerande roll för fysisk inaktivitet som riskfaktor för tidig sjukdom och död. Fysisk inaktivitet är väsentligt farligare än övervikt och är också i många länder redan minst lika stor eller större riskfaktor än rökning. Detta gäller inte bara för typ II diabetes utan också för hjärt-kärl sjukdomar.

I försök med att förklara hur fysisk aktivitet påverkar hälsan kommer de effekter som träning har på skelettmuskulaturen i förgrunden. Kapillärer, lipoproteinlipas, plasmamembranens fosfolipidsammansättning, fett- och glukostransportproteiner och mitokondriell kapacitet är alla faktorer, som spelar en roll för muskelns ämnesomsättning och insulinkänslighet. Förhållanden som alla försämras vid fysisk inaktivitet. Att vara fysiskt inaktiv medför som illustrerats i Fig. 8 en negativ effekt på muskeln s kapacitet att förbruka mättade fettsyror. LDL-K och S-TG stiger och HDL-K faller samtidigt som plasmamembranens fluiditet reduceras. Resultatet blir en ökad insulinresistens, fetma och utveckling av

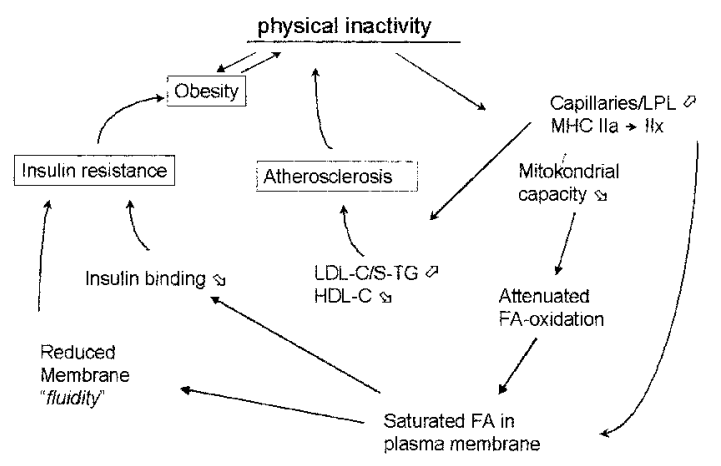

Fig. 8. Schematiskt illustreras hur fysisk inaktivitet kan orsaka en circulus viciosus i skelettmuskulaturen med en minskning av kapillärnätet och mitokondriekapacitet samt en ökning av antalet type IIx muskelfibrer vilket bidrar till utvecklingen av insulinresistens, övervikt och åderförkalkning (40). Nya data antyder också att frånvaro av regelbunden fysisk aktvitet innebär att muskelns interleukin-6 (IL-6) produktion blir minimal och en IL-6 inhiberande effekt på tumour necrosis factor- $\alpha(\mathrm{TNF}-\alpha)$, som bl.a. produceras i fettväven, uteblir. Därmed finns ytterligare en faktor som bidrar till utvecklingen av insulinresistens när man är fysiskt inaktiv (38). LPL: lipoproteinlipase; MHC: myosin heavy chain; LDL-C/S-TG: low-density lipoprotein-cholesterol/serum triglyceride; HDL-C: high-density lipoprotein-cholesterol; FA: fatty acid. 
arterioskleros. Det är en ond cirkel, som är svår men mycket viktig att bryta, då den annars obönhörligen vill medföra en ökad risk för prematur sjukdom och död. Det helt nya i förståelsen av betydelsen av motion är, att IL-6 produceres i muskeln och ev. via en hämning av TNF- $\alpha$ också motverkar utveckling av insulinresistens och typ II diabetes.

\section{Referenser}

Fullständig referenslista fås hos författarna.

Nedan är angivet några nyckelreferenser.

\section{Epidemiologi}

1. Morris JN, Heady JA, Raffle PAB, et al. Coronary heart-disease and physical activity of work. Lancet 1953; i: $1053-7$.

2. Blair SN, Hohl HW, Paffenbarger RS, et al. Physical fitness and all-cause mortality. A prospective study of healthy men and women. JAMA 1989; 262: 2392-401.

6. Haapanen-Niemi N, Vouri I, Pasanen M. Public health burden of coronary heart disease risk factors among middle-aged and elderly men. Prev Med 1999; 28: 343-8.

7. Paffenbarger RS, Hyde RT, Wing AL, et al. The association of changes in physical activity level and other life-style characteristics with mortality among men. N Engl J Med 1993; 328: 538-45.

9. Wei M, Gibbons LW, Mitchell TL, et al. The association between cardiorespiratory fitness and impaired fasting glucose and type 2 diabetes mellitus in men. Ann Intern Med 1999; 130: 89-96.

\section{Allmän biokemi/molekulär biologi}

3. Saltin B, Gollnick PD. Skeletal muscle adaptability: significance for metabolism and performance. In: Peachey LD, Adrian RH, eds. Handbook of physiology - skeletal muscle. American Physiological Society, Baltimore, USA 1983: 555-631.

10. Henriksson J, Reitman JS. Time course of changes in human skeletal muscle succinate dehydrogenase and cytochrome oxidase activities and maximal oxygen uptake with physical activity and inactivity. Acta Physiol Scand 1981; 99: 91-7.

15. Richter EA, Derave W, Wojtaszewski J. Glucose, exercise and insulin: emerging concepts. Topical review. J Physiol 2001; 535: 313-22.

18. Pilegaard H, Ordway GA, Saltin B, Neufer PD. Transcriptional regulation of gene expression in human skeletal muscle during recovery from exercise. Am J Physiol 2000; 279: E806-14.
28. Pilegaard H, Keller C, Steensberg A, et al. Influence of pre-exercise muscle glycogen content on exercise-induced transcriptional regulation of metabolic genes. $\mathbf{J}$ Physiol 2002; 541: 261-271.

38. Pedersen BK, Steensberg A, Schjerling P. Musclederived interleukin-6 - possible biological effects. A topical review. J Physiol 2001; 536; 329-37.

\section{Fett metabolism}

12. Kiens B, Essén-Gustavsson B, Christensen NJ, Saltin B. Skeletal muscle substrate utilization during submaximal exercise in man: effect of endurance training. J Physiol 1993; 469: 459-78.

13. Kiens B, Lithell H. Lipoprotein metabolism influenced by training-induced changes in human skeletal muscle. J Clin Invest 1989; 83: 558-64.

17. Shono N, Urata H, Saltin B, et al. Effects of low intensity aerobic training on skeletal muscle capillary and blood lipoprotein profiles. J Atheroscler Thromb 2002: 9: 78-85.

33. Andersson A, Sjödin A, Olsson R, Vessby B. Effects of physical exercise on phospholipid fatty acid composition in skeletal muscle. Am J Physiol 1998; 274: E432-8.

36. Helge JW, Kriketos AD, Storlien LH. Insulin sensitivity, muscle fibre types and membrane lipids. In: Richter EA, Kiens B, Galbo H, et al., eds. Advances in Experimental Medicine and Biology 441. Skeletal muscle metabolism in exercise and diabetes. New York: Plenum Press, 1998: 129-38.

39. Wallenius V, Wallenius K, Ahren B, et al. Interleukin-6deficient mice develop mature-onset obesity. Nat Med 2002; 8: 75-9.

\section{Kolhydrat metabolism}

19. Dela F, Vaag AA. Fysisk træning til behandlingen af type 2-diabetes. U geskr Læger 2000; 162: 2185-9.

21. Lund S, Holman GD, Schmitz O, Pedersen O. Contraction stimulates translocation of glucose transporter GLUT4 in skeletal muscle through a mechanism distinct from that of insulin. Proc Natl Acad Sci USA 1995; 92: $5817-21$.

37. Lindgärde $F$, Saltin $B$, Daily physical activity, work capacity and glucose tolerance in lean and obese normoglycaemic middle-aged men. Diabetologica 1981; 20: $134-8$.

\section{B. Saltin, CMRC}

Rigshospitalet 7652, Blegdamsvej 9, DK-2I00 Köpenhamn $\varnothing$, Denmark.

E-mail: cmrc@rh.dk 